\title{
Improving risk prediction for pancreatic cancer in symptomatic patients: a Saudi Arabian study
}

This article was published in the following Dove Press journal:

Cancer Management and Research

\author{
Anwar E Ahmed ${ }^{1,2}$ \\ Faris S Alzahrani ${ }^{2}$ \\ Ahmed M Gharawi ${ }^{2}$ \\ Salman A Alammary ${ }^{2}$ \\ Fahad H Almijmaj ${ }^{2}$ \\ Fahad M Alhusayni \\ Donna K McClish ${ }^{3}$ \\ Hamdan Al-Jahdali ${ }^{1,2}$ \\ Ashwaq A Al Olayan ${ }^{4}$ \\ Abdul Rahman Jazieh ${ }^{4}$ \\ 'King Abdullah International Medical \\ Research Center (KAIMRC), Riyadh, \\ Saudi Arabia; ${ }^{2}$ King Saud Bin Abdulaziz \\ University for Health Sciences, \\ Riyadh, Saudi Arabia; ${ }^{3}$ Department \\ of Biostatistics, School of Medicine, \\ Virginia Commonwealth University, \\ Richmond, VA, USA; ${ }^{4}$ King Abdulaziz \\ Medical City, National Guards Health \\ Affairs, Riyadh, Saudi Arabia
}

Correspondence: Anwar E Ahmed College of Public Health and Health Informatics, King Saud Bin Abdulaziz University for Health Sciences, MC 2350, PO Box 22490, Riyadh, II426, Saudi Arabia

Tel +966 II 4295415

Email ahmeda5@vcu.edu
Background: Imaging tests used in our center are usually inadequate to confirm the high risk for pancreatic cancer. We aimed to use a combination of potential predictors including imaging tests to quantify the risk of pancreatic cancer and evaluate its utility.

Methods: This was a retrospective cohort study of patients who were suspected as having pancreatic cancer and underwent biopsy examination of pancreatic mass at King Abdulaziz Medical City, Riyadh, Saudi Arabia, between January 1, 2013, and December 31, 2016. We retrieved data on demographics, clinical history, imaging tests, and final pancreatic diagnosis from medical records.

Results: Of the 206 who underwent pancreatic biopsies, the mean age was 63.6 years; $54.4 \%$ were male. Of all the biopsies, $57.8 \%$ were malignant and $42.2 \%$ were benign masses. Nine factors contributed significantly to the risk of pancreatic cancer and were noted: older age (adjusted odds ratio $[\mathrm{aOR}]=1.048 ; P=0.010)$, male gender $(\mathrm{aOR}=4.670 ; P=0.008)$, weight loss $(\mathrm{aOR}=14.810 ; P=0.001)$, abdominal pain $(\mathrm{aOR}=7.053 ; P=0.0 .001)$, blood clots $(\mathrm{aOR}=20.787$; $P=0.014)$, pancreatitis ( $\mathrm{aOR}=4.473 ; P=0.021)$, jaundice (aOR $=7.446 ; P=0.003)$, persistent fatigue $(\mathrm{aOR}=22.015 ; P=0.015)$, and abnormal imaging tests $(\mathrm{aOR}=67.124 ; P=0.001)$. The model yielded powerful calibration $(P=0.953)$, excellent predictive utility (area under the receiver operating characteristic curve $96.3 \% ; 95 \% \mathrm{CI}=94.1,98.6$ ), with optimism-corrected area under the curve bootstrap resampling of $94.9 \%$. An optimal cut-off risk probability of 0.513 yielded a sensitivity of $94 \%$ and specificity of $84.7 \%$ for risk classification.

Conclusion: The study developed and validated a risk model for quantifying the risk of pancreatic cancer. Nine characteristics were associated with increased risk of pancreatic cancer. This risk assessment model is feasible and highly sensitive and could be useful to improve screening performance and the decision-making process in clinical settings in Saudi Arabia.

Keywords: pancreas, cancer, fatigue, weight loss, blood clots, jaundice, Saudi Arabia

\section{Introduction}

Pancreatic cancer is the deadliest form of cancer in Saudi Arabia, with a 5-year survival rate of $10 \%{ }^{1}$ In 2003, the Saudi Cancer Registry reported 101 newly diagnosed pancreatic cancers (36 women and 65 men). ${ }^{2}$ However, the Saudi Cancer Registry's most recent report for cancers (2014) revealed 277 newly diagnosed pancreatic cancer cases (102 women and 175 men). ${ }^{3}$ These indicate that the number of new pancreatic cancer cases increased significantly over a period of 10 years in Saudi Arabia, an increase of $174.26 \%$.

Most international pancreatic cancer cases are diagnosed at advanced stages, ${ }^{4}$ similar to the situation in Saudi Arabia. ${ }^{1-3}$ Detecting pancreatic cancer at an early stage 
may improve survival rates, ${ }^{5}$ as there would be more treatment options. ${ }^{6}$ Although imaging tests such as computerized tomography (CT scan), magnetic resonance imaging (MRI), and ultrasound (US) are most commonly applied for early detection of pancreatic cancer, their predictive performance has yet to be established in Saudi Arabia. However, an individual test alone may not have sufficient predictive ability to correctly classify true positive and negative patients. ${ }^{7,8}$

Based on existing literature, factors associated with pancreatic cancer have been well established in international populations..$^{9-12}$ These include male gender, ${ }^{9}$ older age, ${ }^{9}$ pancreatitis, ${ }^{10}$ smoking,${ }^{10}$ obesity, ${ }^{10}$ diabetes, ${ }^{10,11}$ jaundice,,${ }^{11}$ abdominal pain, ${ }^{11}$ nausea/vomiting, ${ }^{11}$ fatigue, ${ }^{12}$ and weight loss. ${ }^{12}$ There is no adequate information available on clinical predictors of pancreatic cancer in Saudi Arabia; ${ }^{13}$ as also, there is no valid assessment tool to identify patients at high risk of pancreatic cancer in this population.

There is an urgent need to establish a risk model to screen for high risk of pancreatic cancer in Saudi Arabia. This risk model represents the first model to discriminate between low-risk and high-risk pancreatic cancer in Saudi Arabia. This model incorporates demographic, clinical, and radiological variables to improve early detection of pancreatic cancer. We aimed to develop a risk prediction model for pancreatic cancer and assess its utility on a retrospective study of patients who underwent biopsy examination of pancreatic mass at King Abdulaziz Medical City (KAMC), Riyadh, Saudi Arabia, between January 1, 2013, and December 31, 2016.

\section{Materials and methods}

This was a single center retrospective cohort study of patients who were suspected of having pancreatic cancer and who underwent biopsy examination of pancreatic mass at KAMC, Riyadh between January 1, 2013, and December 31, 2016. KAMC diagnoses and treats many pancreatic cancer patients and is committed to establishing early detection and diagnosis programs.

Data were retrieved from medical records. The authors extracted the following demographic data: age/years, gender, height $/ \mathrm{m}$, and weight $/ \mathrm{kg}$. The body mass index (BMI) was calculated using the formula weight $/ \mathrm{kg} /(\text { height } / \mathrm{m})^{2}$ and classified into obese $(\mathrm{BMI} \geq 30$ ) or not obese (BMI <30). The authors extracted data on symptoms (yes/no) of pancreatic cancer: nausea/vomiting, jaundice, weight loss, dark urine, persistent fatigue, abdominal pain, back pain, bowel obstruction, blood clots, and pancreatitis.

The authors retrieved data on comorbidities (yes/no): diabetes, hypertension, depression, and renal disease. The clinical findings of the imaging tests for each patient were reviewed: US, CT scan, and MRI. An abnormal imaging finding was recorded if at least one of these imaging tests was abnormal. The final diagnosis was recorded for each patient and classified into benign or malignant masses.

\section{Statistical analyses}

Data analysis was performed using STATA 12.1 (StataCorp LP, College Station, TX, USA). Continuous characteristics were presented in the form of mean and standard deviation, while categorical characteristics were presented in the form of frequency and percent (Table 1). Subgroup analyses, independent $t$-tests and chi-squared tests, were used to identify significant individual predictors for malignant pancreatic mass (Table 1). The discrimination accuracy for individual predictors was calculated in the form of area under curve (AUC) and 95\% CI for AUC. The stepwise binary logistic approach (Table 2) was used to retain only predictors with small $P$-value $(P \leq 0.05)$. Calibration of the model was assessed by Hosmer-Lemeshow chi-square goodness-of-fit test, with a $P>0.05$ indicating an acceptable calibration. The model for predictive accuracy was assessed using (c-statistic) AUC and 95\% CI. Model validation of predictive accuracy was assessed by calculating the bootstrap ${ }^{14}$ optimism-corrected AUC with 200 bootstrap replications from the actual sample. An optimal probability cut-off value was determined using the Youden Index (YI) ${ }^{15}$ for discriminating between benign and malignant pancreatic masses. The diagnostic performance of the risk prediction model was compared with the most important predictors using receiver operating characteristic AUC, as shown in Figure 1.

\section{Ethical considerations}

The study received ethical approval from the Institutional Review Board at the Ministry of National Guard Health Affairs (Study Number: SP17/028/R), Riyadh, Saudi Arabia. Due to the nature of the study design, consent from patients to review medical records was not required by the Ethical Review Committee at the Ministry of National Guard Health Affairs. Data were deidentified to protect patient information confidentiality and privacy.

\section{Results}

Of the 206 patients who underwent pancreatic biopsy and were analyzed, the results show the mean age was 63.6 years; $54.4 \%$ were male. Of the 206 biopsied samples, $57.8 \%$ were malignant and $42.2 \%$ revealed benign masses. The majority, $56.8 \%$, had diabetes, $60.2 \%$ had hypertension, and $64.6 \%$ had abdominal pain. 
Table I Characteristics of patients who underwent pancreatic biopsy

\begin{tabular}{|c|c|c|c|c|c|c|c|c|c|c|}
\hline \multirow[t]{2}{*}{ Predictors } & \multicolumn{2}{|c|}{$\begin{array}{l}\text { Overall, } \\
N=206\end{array}$} & \multicolumn{2}{|c|}{$\begin{array}{l}\text { Benign, } 87 \\
(42.2 \%)\end{array}$} & \multicolumn{2}{|c|}{$\begin{array}{l}\text { Malignant, I I } 9 \\
(57.8 \%)\end{array}$} & \multirow[t]{2}{*}{$P$-value } & \multirow[t]{2}{*}{ OR } & \multicolumn{2}{|c|}{$95 \% \mathrm{Cl}$ for $\mathrm{OR}$} \\
\hline & Mean & SD & Mean & SD & Mean & SD & & & Lower & Upper \\
\hline \multirow[t]{2}{*}{ Age ( $15-95$ years) } & 63.6 & 16.3 & 59.9 & 20.2 & 66.3 & 12.2 & 0.007 & 1.025 & 1.007 & 1.043 \\
\hline & $n$ & $\%$ & $n$ & $\%$ & $\mathbf{n}$ & $\%$ & & & & \\
\hline Obesity BMI $\geq 30$ & 47 & 24.4 & 22 & 26.5 & 25 & 22.7 & 0.545 & 0.816 & 0.421 & 1.579 \\
\hline Male & 112 & 54.4 & 34 & 39.1 & 78 & 65.5 & $0.00 \mathrm{I}^{\mathrm{a}}$ & 2.966 & 1.672 & 5.260 \\
\hline Diabetes & 117 & 56.8 & 37 & 42.5 & 80 & 67.2 & $0.00 I^{a}$ & 2.772 & 1.565 & 4.911 \\
\hline Hypertension & 124 & 60.2 & 52 & 59.8 & 72 & 60.5 & 0.915 & 1.031 & 0.586 & 1.813 \\
\hline Renal disease & 34 & 16.5 & 19 & 21.8 & 15 & 12.6 & 0.081 & 0.516 & 0.246 & 1.085 \\
\hline Nausea/vomiting & 75 & 36.4 & 24 & 27.6 & 51 & 42.9 & $0.025^{\mathrm{a}}$ & 1.969 & 1.087 & 3.566 \\
\hline Jaundice & 61 & 29.6 & 6 & 6.9 & 55 & 46.2 & $0.00 I^{a}$ & 11.602 & 4.697 & 28.655 \\
\hline Weight loss & 61 & 29.6 & 5 & 5.7 & 56 & 47.1 & $0.00 I^{a}$ & 14.578 & 5.515 & 38.531 \\
\hline Dark urine & 28 & 13.6 & I & 1.1 & 27 & 22.7 & $0.002^{\mathrm{a}}$ & 25.239 & 3.357 & 189.779 \\
\hline Persistent fatigue & 23 & 11.2 & 2 & 2.3 & 21 & 17.6 & $0.003^{a}$ & 9.107 & 2.075 & 39.975 \\
\hline Abdominal pain & 133 & 64.6 & 40 & 46.0 & 93 & 78.2 & $0.00 \mathrm{I}^{\mathrm{a}}$ & 4.203 & 2.294 & 7.702 \\
\hline Back pain & 24 & 11.7 & I & I.I & 23 & 19.3 & $0.003^{\mathrm{a}}$ & 20.604 & 2.725 & 155.809 \\
\hline Bowel obstruction & 20 & 9.7 & 3 & 3.4 & 17 & 14.3 & $0.017^{\mathrm{a}}$ & 4.667 & 1.323 & 16.467 \\
\hline Blood clots & 12 & 5.8 & 4 & 4.6 & 8 & 6.7 & 0.522 & 1.495 & 0.436 & 5.134 \\
\hline Pancreatitis & 59 & 28.6 & 11 & 12.6 & 48 & 40.3 & $0.00 I^{a}$ & 4.671 & 2.249 & 9.699 \\
\hline Abnormal imaging findings & 154 & 76.6 & 39 & 45.9 & 115 & 99.1 & $0.00 I^{\mathrm{a}}$ & $|35.64|$ & 18.099 & $1,016.560$ \\
\hline
\end{tabular}

Note: aSignificant at $\alpha=0.05$.

Abbreviations: BMI, body mass index; OR, odds ratio.

Table 2 Risk prediction model of pancreatic malignancy

\begin{tabular}{|c|c|c|c|c|c|c|}
\hline \multirow[t]{2}{*}{ Predictors } & \multirow[t]{2}{*}{ B } & \multirow[t]{2}{*}{ SE } & \multirow[t]{2}{*}{$P$-value } & \multirow[t]{2}{*}{ aOR } & \multicolumn{2}{|c|}{ 95\% Cl for aOR } \\
\hline & & & & & Lower & Upper \\
\hline Age & 0.047 & 0.018 & $0.010^{\mathrm{a}}$ & 1.048 & 1.011 & 1.086 \\
\hline Gender & $1.54 \mid$ & 0.577 & $0.008^{a}$ & 4.670 & 1.507 & 14.473 \\
\hline Weight loss & 2.695 & 0.742 & $0.000^{\mathrm{a}}$ & 14.810 & 3.457 & 63.449 \\
\hline Abdominal pain & 1.953 & 0.615 & $0.00 I^{a}$ & 7.053 & 2.113 & 23.548 \\
\hline Blood clots & 3.034 & 1.236 & $0.014^{\mathrm{a}}$ & 20.787 & 1.843 & 234.513 \\
\hline Pancreatitis & 1.498 & 0.649 & $0.02 \mathrm{I}^{\mathrm{a}}$ & 4.473 & 1.253 & 15.967 \\
\hline Jaundice & 2.008 & 0.682 & $0.003^{\mathrm{a}}$ & 7.446 & 1.955 & 28.360 \\
\hline Persistent fatigue & 3.092 & 1.276 & $0.015^{\mathrm{a}}$ & 22.015 & 1.806 & 268.416 \\
\hline Abnormal imaging findings & 4.207 & 1.139 & $0.00 I^{a}$ & 67.124 & 7.199 & 625.876 \\
\hline Constant & -10.044 & 1.918 & $0.00 I^{\mathrm{a}}$ & & & \\
\hline
\end{tabular}

Note: aStepwise selection significant at $\alpha=0.05$.

Abbreviation: aOR, adjusted odds ratio.

According to the subgroup analysis in Table 1, the malignant pancreatic group had a significantly higher percent of patients who were of older age, male gender, had diabetes, nausea/vomiting, jaundice, weight loss, dark urine, persistent fatigue, abdominal pain, back pain, bowel obstruction, and pancreatitis, and had abnormal imaging finding compared with the benign pancreatic group. The ability of individual predictors in predicting malignant pancreatic mass was calculated. Abnormal imaging finding $(\mathrm{AUC}=0.766)$ and weight loss $(\mathrm{AUC}=0.707)$ had the strongest predictive accuracy.
Stepwise binary logistic analysis (Table 2) indicated that older age (adjusted odds ratio $[\mathrm{aOR}]=1.048 ; 95 \% \mathrm{CI}=1.011,1.086$ ), male gender $(\mathrm{aOR}=4.670 ; 95 \% \mathrm{CI}=1.507,14.473)$, weight loss $(\mathrm{aOR}=14.810 ; 95 \% \mathrm{CI}=3.457,63.449)$, abdominal pain ( $\mathrm{aOR}$ $=7.053 ; 95 \% \mathrm{CI}=2.113,23.548)$, blood clots $(\mathrm{aOR}=20.787$; $95 \% \mathrm{CI}=1.843,234.513)$, pancreatitis $(\mathrm{aOR}=4.473 ; 95 \% \mathrm{CI}$ $=1.253,15.967)$, jaundice $(\mathrm{aOR}=7.446 ; 95 \% \mathrm{CI}=1.955,28.360)$, persistent fatigue ( $\mathrm{aOR}=22.015 ; 95 \% \mathrm{CI}=1.806,268.416$ ), and abnormal imaging finding $(\mathrm{aOR}=67.124 ; 95 \% \mathrm{CI}=7.199$, 625.876 ) significantly predicted malignant pancreatic mass. 


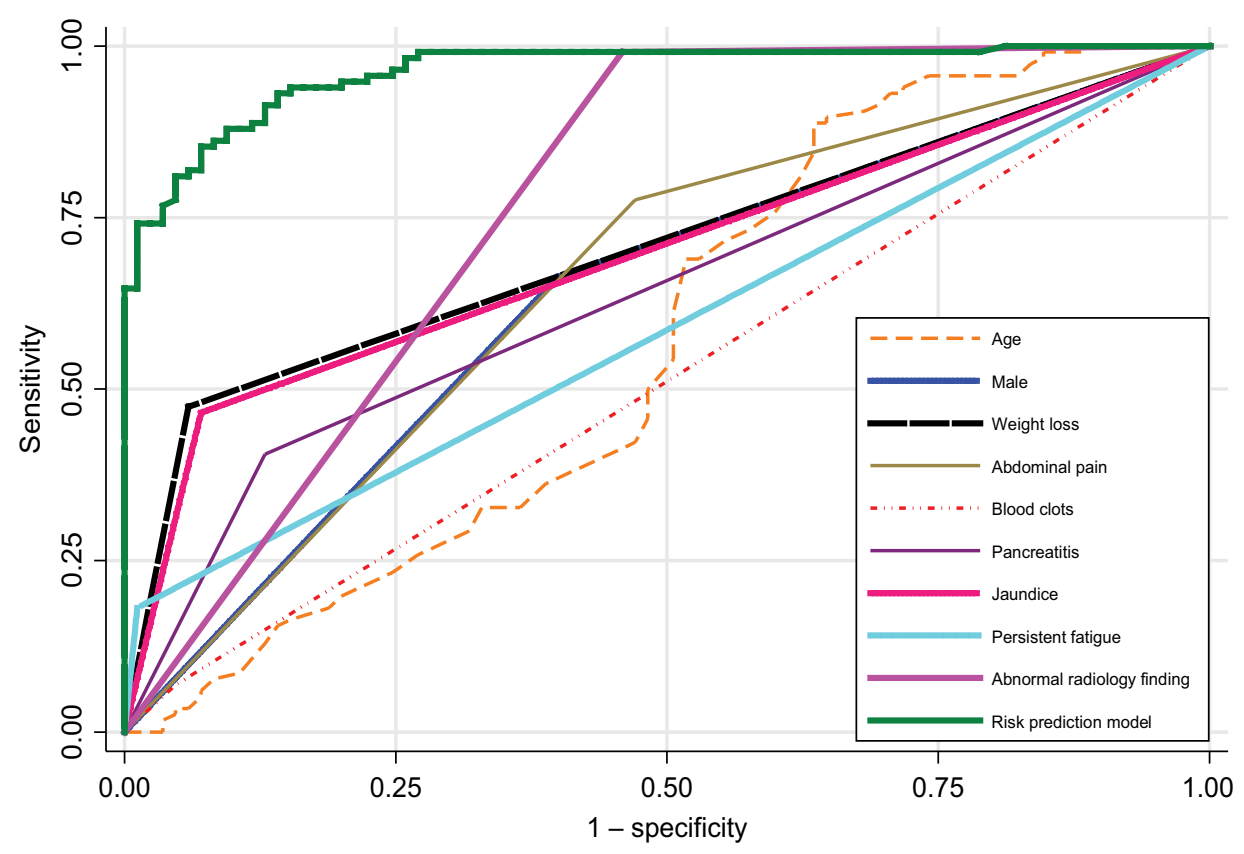

Figure I ROC curve of the risk prediction model as compared to each predictor alone. Abbreviation: ROC, receiver operating characteristic.

The model showed powerful calibration to predict malignant pancreatic mass with Hosmer-Lemeshow Chi-square goodness-of-fit $(P=0.953)$. The predictive utility of the model for discriminating malignant from benign pancreatic masses was excellent ( $\mathrm{AUC}=96.3 \% ; 95 \% \mathrm{CI}=94.1,98.6)$ with the optimal cut-off risk probability of 0.513 yielding a sensitivity of $94 \%$ and specificity of $84.7 \%$. The optimism-corrected AUC bootstrap resampling of the model was $94.9 \%$.

\section{Discussion}

This study established the first risk assessment tool for prediction of pancreatic cancer in Saudi Arabia. A retrospective study was implemented for patients who were suspected of having pancreatic malignancy and underwent biopsy examination of pancreatic mass at KAMC, Riyadh between January 1, 2013, and December 31, 2016. Imaging tests are widely used in the center to screen for pancreatic cancer lesions. Their accuracy of screening programs was found to be $76.6 \%$ in patients suspected as having pancreatic cancer. This confirms that the predictive ability of the imaging tests may not be sufficient to detect the high risk of pancreatic cancer. ${ }^{16}$

The authors were able to improve the accuracy of the screening process for pancreatic malignancy. The model had adequate goodness-of-fit with excellent discrimination
(96.3\%) and was internally valid (corrected AUC $=94.9 \%$ ) according to the bootstrapping technique. The risk model consisted of the following nine characteristics: age, male gender, weight loss, abdominal pain, blood clots, pancreatitis, jaundice, persistent fatigue, and abnormal imaging finding. The combination of these nine characteristics increases the risk of malignant pancreatic mass as compared to the utility of each individual factor alone (Figure 1). The model is feasible as these characteristics are routinely assessed in daily clinical practice in our center. Thus, the model may help identify patients at high risk of pancreatic cancer and improve early detection. The screening accuracy of this model would have to be validated in a large prospective study.

In this study, we observed the risk of pancreatic cancer associated with increased age. This is widely consistent with previous international studies, ${ }^{9,17,18}$ in which older age as having a considerable association with the risk of pancreatic cancer has been documented. A national screening program targeting older individuals may help in early detection ${ }^{5}$ and could provide wide treatment options for pancreatic cancer. ${ }^{6}$ Our finding was broadly consistent with earlier studies, ${ }^{9,18,19}$ with a significant increase in the risk of pancreatic cancer being found among the male gender.

Certain risk factors and symptoms have been widely reported to increase the risk of pancreatic cancer. ${ }^{9-12,20-25}$ 
These results were highlighted in our study, with abdominal pain, weight loss, blood clots, pancreatitis, jaundice, and persistent fatigue being potential indicators of high-risk pancreatic malignancy. The presence of these factors could be attributed to the development and progress of the tumor. ${ }^{20-22}$ Some of these factors may be connected with lifestyle and lack of physical activity. ${ }^{23-25}$ Recognizing the manifestation of pancreatic cancer may assist specialists and general practitioners in prompt decision-making and improve the early diagnosis process.

Several noteworthy limitations have to be mentioned. First, generalization of findings is limited to our center, as the study was based on a single center rather than a multicenter setting. Second, the model was developed and internally validated in a cohort as a retrospective study; external validation is needed in a cohort done as a prospective study. Third, due to the nature of the study design, we were not able to assess a number of potential factors such as smoking status, healthy diet, and alcohol use. ${ }^{25}$ Despite the limitations, there is an urgent need for a simple and highly sensitive assessment tool for pancreatic cancer for use in clinical settings in Saudi Arabia.

\section{Conclusion}

The study developed and validated a feasible risk model for quantifying the risk of pancreatic cancer. Nine characteristics were associated with increased risk of pancreatic cancer; these were older age, male gender, weight loss, abdominal pain, blood clots, pancreatitis, jaundice, persistent fatigue, and abnormal imaging findings. This risk assessment model is simple and highly sensitive and could be useful to improve the screening performance and decision-making process in clinical settings.

\section{Informed consent}

Due to the type of the study design, requirement for formal consent was waived by the institutional review board at the Ministry of National Guard Health Affairs.

\section{Acknowledgment}

The authors would like to thank King Abdullah International Medical Research Center (KAIMRC), Ministry of National Guard Health Affairs, Riyadh, Saudi Arabia, for approving the study.

\section{Disclosure}

The authors report no conflicts of interest in this work.

\section{References}

1. Alghamdi HJ, Alfaifi SA, Alolayan AA, Musaad SM, Jazieh AM. Pancreatic cancer in Saudi patients treated at tertiary institution. Ten years retrospective study. Saudi Med J. 2013;34(6):604-608.

2. Saudi Cancer Registry. Cancer Incidence Report Saudi Arabia 2003. Saudi Arabia: Saudi Cancer Registry (SCR). Available from: https:// nhic.gov.sa/eServices/Documents/Incidence\%20Report\%202003.pdf. Accessed October 11, 2018.

3. Saudi Cancer Registry. Cancer Incidence Report Saudi Arabia 2014. Saudi Arabia: Saudi Cancer Registry (SCR). Available from: www.nhic. gov.sa/eServices/Documents/2014.pdf. Accessed October 11, 2018.

4. Gedge K. Pancreatic cancer: a symptomless killer. J Perioper Pract. 2017;27(7-8):158-161.

5. Hanada K, Okazaki A, Hirano N, et al. Diagnostic strategies for early pancreatic cancer. J Gastroenterol. 2015;50(2):147-154.

6. Tran Cao HS, Zhang Q, Sada YH, et al. Value of lymph node positivity in treatment planning for early stage pancreatic cancer. Surgery. 2017;162(3):557-567.

7. Ahmed AE, McClish DK, Schubert CM. Accuracy and cost comparison in medical testing using sequential testing strategies. Stat Med. 2011;30(29):3416-3430.

8. Ahmed AE, Schubert CM, McClish DK. Reducing cost in sequential testing: a limit of indifference approach. Stat Med.2013;32(16):2715-2727.

9. Villanueva CE, Plasencia JA, Quiroz EF, Arrascue JL. Tendencias en la Incidencia y Factores de Riesgo Asociados al Desarrollo de Cáncer de Páncreas. Instituto Regional de Enfermedades Neoplásicas "Dr. Luis Pinillos Ganoza"-IREN Norte. 2008-2011. [Trends in incidence and risk factors associated with the development of pancreatic cancer. Regional Institute of Neoplastic Diseases "Dr. Luis Pinillos Ganoza “- Iren North 2008 - 2011]. Rev Gastroenterol Peru. 2012;32(2):161-168. Spanish.

10. McWilliams RR, Maisonneuve P, Bamlet WR, et al. Risk factors for early-onset and very-early-onset pancreatic adenocarcinoma: a pancreatic cancer case-control consortium (PanC4) analysis. Pancreas. 2016;45(2):311-316.

11. Stapley S, Peters TJ, Neal RD, Rose PW, Walter FM, Hamilton W. The risk of pancreatic cancer in symptomatic patients in primary care: a large case-control study using electronic records. Br J Cancer. 2012;106(12):1940-1944.

12. Olson SH, Xu Y, Herzog K, et al. Weight Loss, Diabetes, Fatigue, and Depression Preceding Pancreatic Cancer. Pancreas. 2016;45(7):986-991.

13. Almadi MA, Alharbi O, Azzam N, et al. Clinical predictors of resectability of pancreatic adenocarcinoma. Saudi J Gastroenterol. 2013;19(6):278-285.

14. Harrell FE, Lee KL, Mark DB. Multivariable prognostic models: issues in developing models, evaluating assumptions and adequacy, and measuring and reducing errors. Stat Med. 1996;15(4):361-387.

15. Youden WJ. Index for rating diagnostic tests. Cancer. 1950;3(1):32-35.

16. Tamm EP, Loyer EM, Faria SC, Evans DB, Wolff RA, Charnsangavej C. Retrospective analysis of dual-phase MDCT and follow-up EUS/ EUS-FNA in the diagnosis of pancreatic cancer. Abdom Imaging. 2007;32(5):660-667.

17. Boursi B, Finkelman B, Giantonio BJ, et al. A clinical prediction model to assess risk for pancreatic cancer among patients with new-onset diabetes. Gastroenterology. 2017;152(4):840-850.

18. Yu A, Woo SM, Joo J, et al. Development and validation of a prediction model to estimate individual risk of pancreatic cancer. PLoS One. 2016;11(1):e0146473.

19. Cai QC, Chen Y, Xiao Y, et al. A prediction rule for estimating pancreatic cancer risk in chronic pancreatitis patients with focal pancreatic mass lesions with prior negative EUS-FNA cytology. Scand J Gastroenterol. 2011;46(4):464-470.

20. Stapley S, Peters TJ, Neal RD, Rose PW, Walter FM, Hamilton W. The risk of pancreatic cancer in symptomatic patients in primary care: a large case-control study using electronic records. Br J Cancer. 2012;106(12):1940-1944. 
21. Frič P, Šedo A, Škrha J, et al. Early detection of sporadic pancreatic cancer: time for change. Eur J Gastroenterol Hepatol. 2017;29(8):885-891.

22. Holly EA, Chaliha I, Bracci PM, Gautam M. Signs and symptoms of pancreatic cancer: a population-based case-control study in the San Francisco Bay area. Clin Gastroenterol Hepatol. 2004;2(6): 510-517.

23. Otsuki M, Tashiro M. Chronic pancreatitis, pancreatic cancer and life style. Nihon Naika Gakkai Zasshi. 2005;94(9):1872-1877.
24. Neuzillet C, Vergnault M, Bonnetain F, Hammel P. Rationale and design of the Adapted Physical Activity in advanced Pancreatic Cancer patients (APACaP) GERCOR (Groupe Coopérateur Multidisciplinaire en Oncologie) trial: study protocol for a randomized controlled trial. Trials. 2015;16:454.

25. Lu XH, Wang L, Li H, Qian JM, Deng RX, Zhou L. Establishment of risk model for pancreatic cancer in Chinese Han population. World $J$ Gastroenterol. 2006;12(14):2229-2234.

\section{Publish your work in this journal}

Cancer Management and Research is an international, peer-reviewed open access journal focusing on cancer research and the optimal use of preventative and integrated treatment interventions to achieve improved outcomes, enhanced survival and quality of life for the cancer patient. The manuscript management system is completely online and includes a very quick and fair peer-review system, which is all easy to use. Visit http://www.dovepress.com/testimonials.php to read real quotes from published authors. 